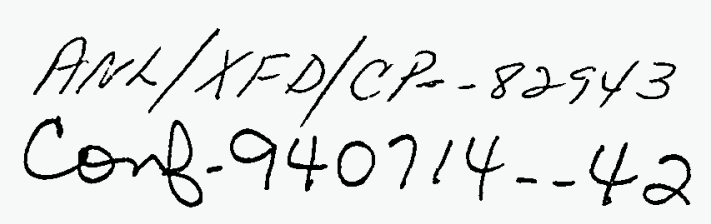

\title{
Beamline Standard Component Designs for The Advanced Photon Source
}

\author{
D. Shu, J. Barraza, C. Brite, J. Chang, T. Sanchez, V. Tcheskidov* \\ and \\ T. M. Kuzay \\ Experimental Facilities Division \\ Advanced Photon Source \\ Argonne National Laboratory \\ Argonne, IL 60439, U.S.A
}

\begin{abstract}
The Advanced Photon Source (APS) has initiated a design standardization and modularization activity for the APS synchrotron radiation beamline components. These standard components are included in components library, sub-components library and experimental station library. This paper briefly describes these standard components using both technical specifications and side view drawings.
\end{abstract}

\section{DISCLAIMER}

\begin{abstract}
This report was prepared as an account of work sponsored by an agency of the United States Government. Neither the United States Government nor any agency thereof, nor any of their employees, makes any warranty, express or implied, or assumes any legal liability or responsibility for the accuracy, completeness, or usefulness of any information, apparatus, product, or process disclosed, or represents that its use would not infringe privately owned rights. Reference herein to any specific commercial product, process, or service by trade name, trademark, manufacturer, or otherwise does not necessarily constitute or imply its endorsement, recommendation, or favoring by the United States Government or any agency thereof. The views and opinions of authors expressed herein do not necessarily state or reflect those of the United States Government or any agency thereof.
\end{abstract} * Visiting engineer from Budker Institute of Nuclear Physics, 630090 Noypsibissk MITED
Russia
DISTRIBUTION OF THIS DOCUMENT IS UNEIMITED 


\section{DISCLAIMER}

Portions of this document may be illegible in electronic image products. Images are produced from the best available original document. 


\section{Introduction}

The Advanced Photon Source (APS) currently under construction at Argonne National Laboratory will generate high brilliance and intense synchrotron radiation from its insertion devices [1] and is scheduled for completion in early 1996. In response to a call for sector beamline proposals, the APS received over 20 from prospective Collaborative Access Teams (CATs)[2].

In 1990, at the start of the APS front-end components development, the APS Experimental Facilities Division initiated a design standardization and modularization activity for the APS beamline components. During the past four years, the APS standard components, which were based on the APS front-end development experiences, passed through many design reviews and prototype $R \& D$ activities. Currently, over 25 different beamline standard components, as well as many subcomponents have been developed and more than 1000 detailed AutoCAD[3] drawings have been released to the APS design exchange system, which is accessible by the APS CATs.

In this paper, a brief technical specification as well as side view drawings of these standard components are presented.

\section{APS generic beamline}

Fig. 1 shows a typical APS beamline, which we call the "TOM-CAT" beamline. It is an insertion device beamline using the APS standard Undulator A as the source [4]. This example shows that the user can design a beamline in which the main beamline components are standardized.

\section{Components library}

The components library contains the designs for filters, slits, shutters, monochromators, mirror mounts, beam position monitors, shielded beam transports and supports. To organize the drawing library, a two-character component name has been identified for each standard component. The first character represents the function of the component, such as $P$ for shutters and $L$ for slits. The second 
character represents the type of component, such as L2 for ID monochromatic-beam slits, and L5 for ID undulator white-beam slits. In some cases, a minor design change has been given to the standard components to suit an application requirement. Therefore, another two digits may follow the first two characters to specify the modified component. For example, T6-21 and T6-26 are two similarly designed optical tables that have the same kinematic mounting structure but different support bases. Fig. 2 shows some of the beamline components designed by the APS. (The $\mathrm{KOHZU}$ monochromator was specified by the APS and designed by Kohzu-Seiki Co.)

Fig. 2 also shows a brief specification for each main component, such as the component flange-to-flange distance (F-F), the optical aperture size (O.A.), the bremsstrahlung shielding aperture size (B.A.) etc. The detailed specifications can be found in many other publications [5-11].

\section{Subcomponents library}

Fig. 3 shows a part of the APS standard subcomponents library. These subcomponents are frequently being used in the APS main components. For example, linear actuators are major sub-components for slits and shutters, and vacuum bellows are used in large quantities in a beamline assembly. The use of standardized and modularly designed subcomponents should result in reduced engineering effort and cost savings for CATs in the areas of beamline special components design.

\section{Experimental station enclosures library}

The APS experimental station construction is modular with standard selfsupporting steel-lead-steel sandwich panels. Fig. 4 shows a typical first optics enclosure. The modular panel design provides users the advantage of being able to expand or modify the enclosure in the future. This drawing library also includes pneumatically operated, as well as manually operated, sliding doors designed for the experimental stations. 
6. Design toolbox for beamline general layout

To simplify the beamline general layout design process, an APS standard components design toolbox has been created. There are two AutoCAD version 12 drawing block libraries in the toolbox, one for the layout sideview and one for the topview. Each drawing block contains the component assembly layout, which is ready to be inserted in the general layout using the AutoCAD insert command or an external reference command. The block reference point is always set on the center of the upstream vacuum flange.

It is possible to put the flange coordinate information of the beamline component into a spreadsheet software, then program AutoCAD using the script command so that AutoCAD can generate the layout automatically by the external reference method using the spreadsheet information [12].

\section{Summary}

The APS beamline standard component libraries were described briefly in this paper. Most of the standard components for the Synchrotron Radiation Instrumentation (SRI) CAT beamlines will be manufactured in 1994.

\section{References}

[1] G.K. Shenoy et al., Status of Advanced Photon Source Project, Int. Symp. on XRay Synchrotron Radiation and Advanced Science and Technology, RIKEN, JAERI, Japan (1990).

[2] D.M. Mills, The Advanced Photon Source: A Status Report, Nucl. Inst. and Meth. A319 (1992) 33-39.

[3] AutoCAD is registered in the U.S. Patent and Trademark Office by Autodesk, Inc..

[4] B. Lai et al., Undulator A Characteristics and Specifications, ANL/APS/TB-3, (1993).

[5] J. Barraza et al., SRI 93, NIST, (1993).

[6] J. Chang et al., Design of a New Coaxial Water-Cooled Photon Shutter, SPIE, 
Vol.1977, pp.451-458 (1993).

[7] C. Brite et al., Beamline Filters Design, SRI 94, Stony Brook (1994)

[8] J. Chang et al., Design of Integral Shutters for the Beamlines at the Advanced Photon Source, SRI 94, Stony Brook (1994)

[9] D. Shu et al., Precision White-Beam Slit Design for High Power Density X-ray Undulator Beamlines at the Advanced Photon Source, SRI 94, Stony Brook (1994).

[10] U. Hahn et al., APS Beamline Standard Components Handbook V.1.3, ANL/APS/LS-187 (1993).

[11] J. Barraza et al., Experimental Station Support Systems for the Advanced Photon Source, SRI 94, Stony Brook (1994).

[12] S.M. Heald, Private communication with D. Shu, (1994)

Figure Captions

Fig. 1, A typical APS beamline: "TOM-CAT" ID beamline general layout.

Fig. 2, APS Standard Components Library Part 1 - Main Components.

Fig. 3, APS Standard Components Library Part 2 - Subcomponents.

Fig. 4, APS Standard Components Library Part 3 - Experimental Stations. 


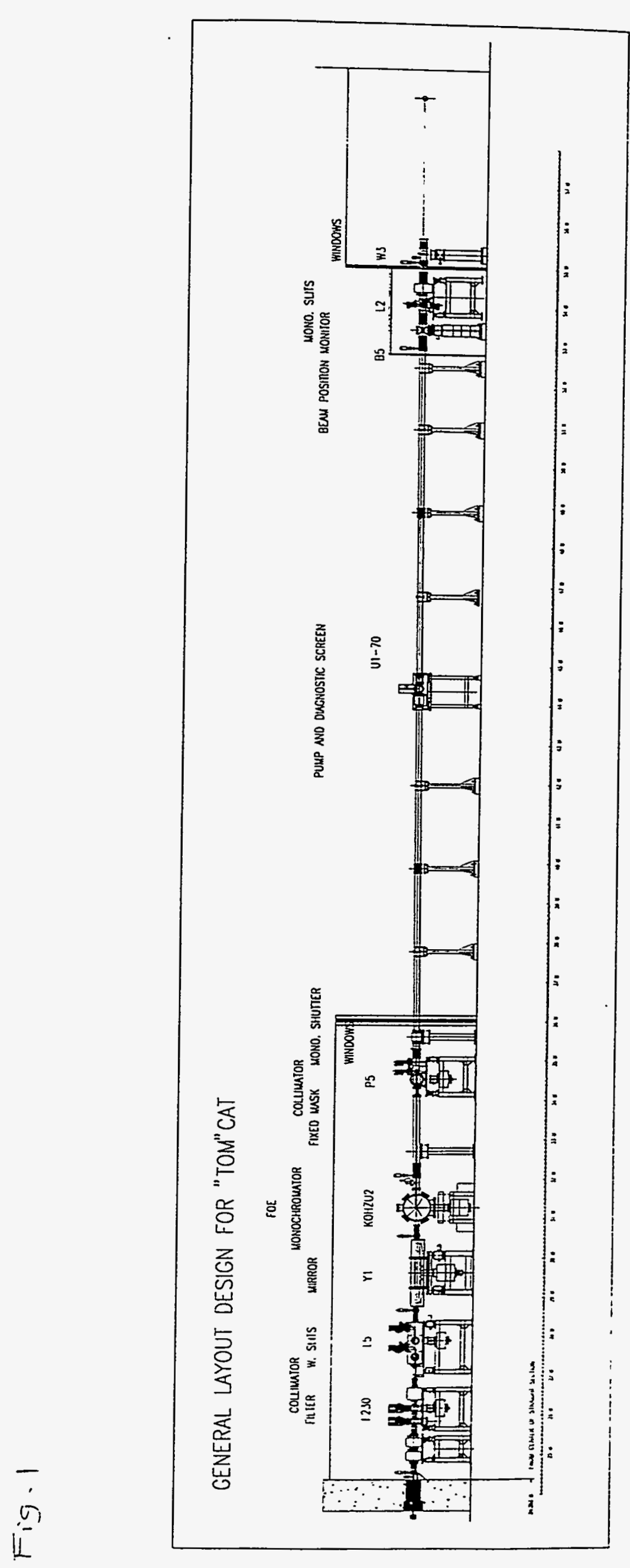

$\because n^{-}=$r. 


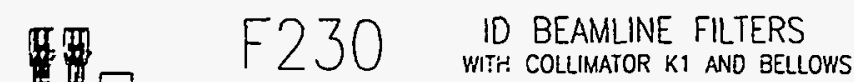

$F-F 575 \mathrm{~mm}+452 \mathrm{~mm}$

O.A. $13 \mathrm{~mm}(\mathrm{~V}) \times 76 \mathrm{~mm}(H)$

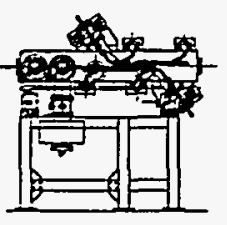

L1 ID U/W WHITE BEAM H\&V SLITS

F $-F 1750 \mathrm{~mm}$

O.A. (IN) $8.5 \mathrm{~mm}(\mathrm{~V}) \times 70 \mathrm{~mm}(\mathrm{H})$

$0 . A$. (OUT) $0-8.5 \mathrm{~mm}(V) \times 0-60 \mathrm{~mm}(\mathrm{H})$

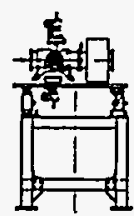

ID MONO. BEAM H\&V SLITS WITH ION PUMP

$F-F 465 \mathrm{~mm}+320 \mathrm{~mm}$

$0 . A .0-30 \mathrm{~mm}(V) \times 0-30 \mathrm{~mm}(H)$

F-F $600 \mathrm{~mm}+475 \mathrm{~mm}$
WITH COLLIMATOR KI AND VALVE

F-F $465 \mathrm{~mm}+320 \mathrm{~mm}$
OA. $0-30 \mathrm{~mm}(\mathrm{~V}) \times 0-120 \mathrm{~mm}(\mathrm{H})$

LS UNDULATOR WHITE BEAM H\&V SLITS
$\begin{aligned} & \text { F-F } 1490 \mathrm{~mm} \\ & \text { OA. (IN) } 20 \mathrm{~mm}(\mathrm{~V}) \times 35 \mathrm{~mm}(\mathrm{H})\end{aligned}$
OA. (OUT) $0-7 \mathrm{~mm}(\mathrm{~V}) \times 0-7 \mathrm{~mm}(\mathrm{H})$

P4 ID INTEGRAL SHUTTERS/STOPS
WHITE BEAM MOVEABLE STOP MITH KIRK KEY
BREMSSTRAHLUNG MOVEABLE STOP WTTH KIRK KEY
DOUBLE MONO. BEAM SHUTERS

P5 ID INTEGRAL SHUTTERS/STOPS
WHITE BEAM FIXEO MASK
BREMSSTRAHLUNG FIXED STOP
DOUELE HONO. BEAM SHUTERS

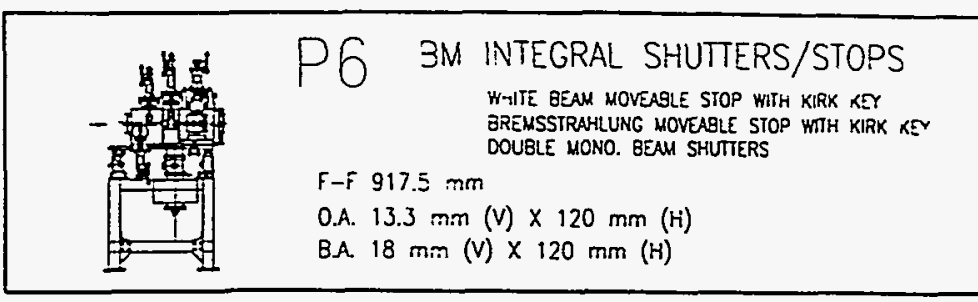

\begin{tabular}{|c|c|}
\hline$\frac{1}{-1}$ & 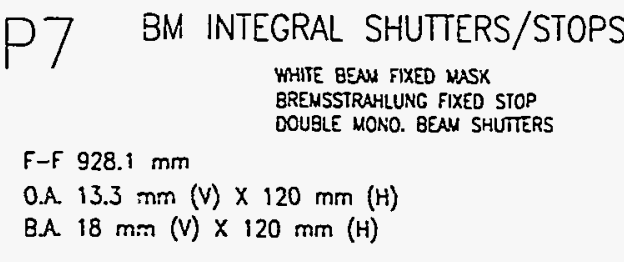 \\
\hline
\end{tabular}

\begin{tabular}{|l|} 
PQ DOUBLE MONO. BEAM SHUTTERS \\
\hline
\end{tabular}
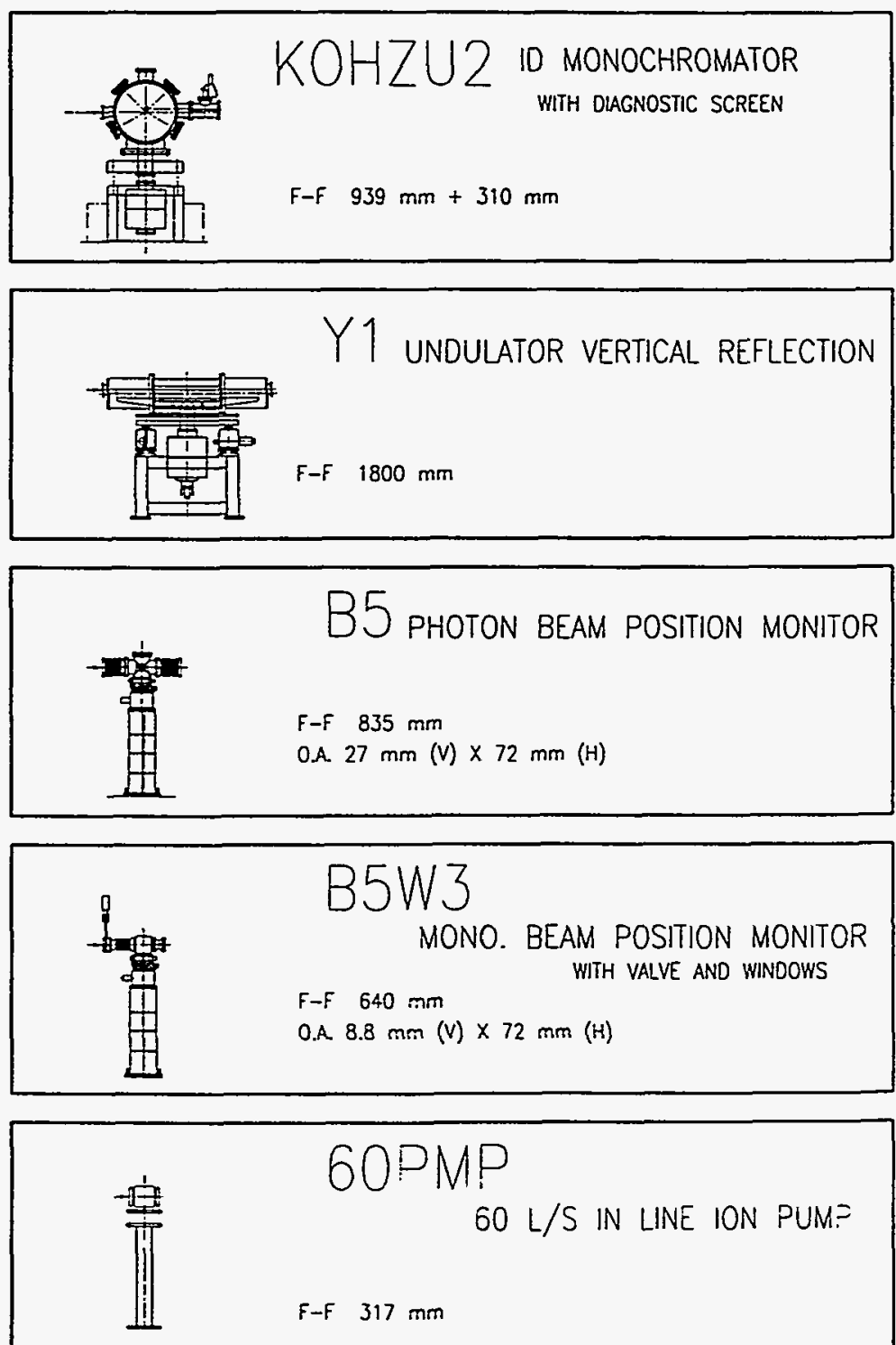


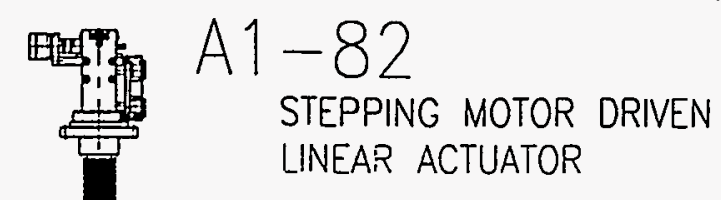

Flange 0.D. $171 \mathrm{~mm}$ Travel Range $30 \mathrm{~mm}$

\section{A1-85}

STEPPING MOTOR DRIVEN

$X-Z$ LINEAR ACTUATOR

Flange 0.D. $253 \mathrm{~mm}$ Travel Ronge $25 \mathrm{~mm}$
A $1-86$
STEPPING MOTOR DRIVEN
LINEAR ACTUATOR

Flange 0.D. $202 \mathrm{~mm}$ Travel Ronge $30 \mathrm{~mm}$

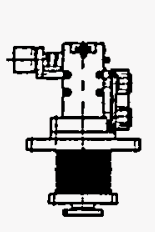

A2 - 82

HEAY LOAD STEPPING MOTOR DRIVEN LINEAR ACTUATOR

Flange 0.D. $253 \mathrm{~mm}$ Travel Range $70 \mathrm{~mm}$

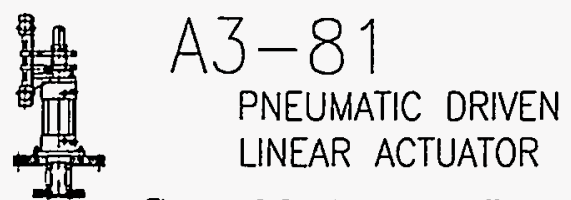

Flange 0.D. $202 \mathrm{~mm}$ Trovel Range $31 \mathrm{~mm}$

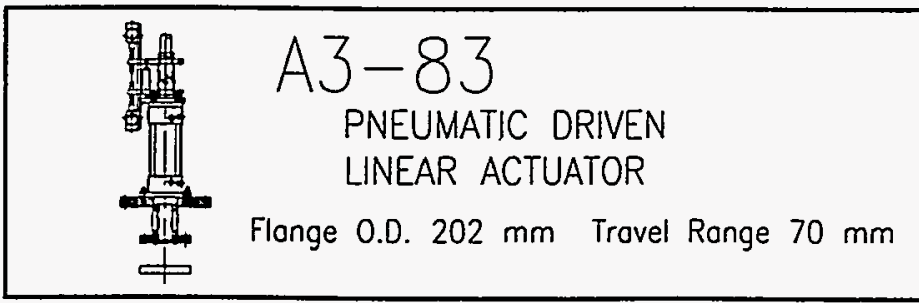

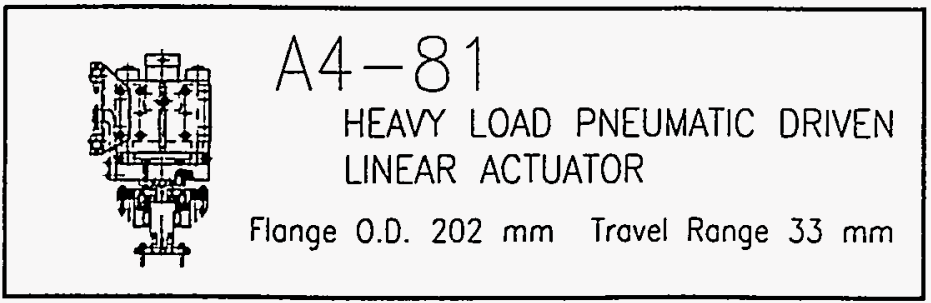

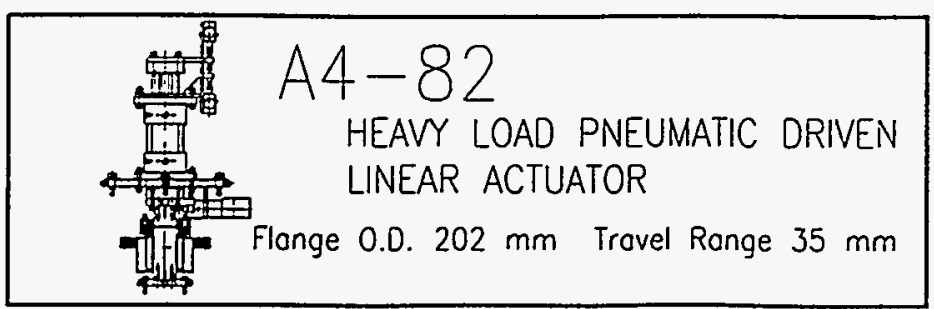



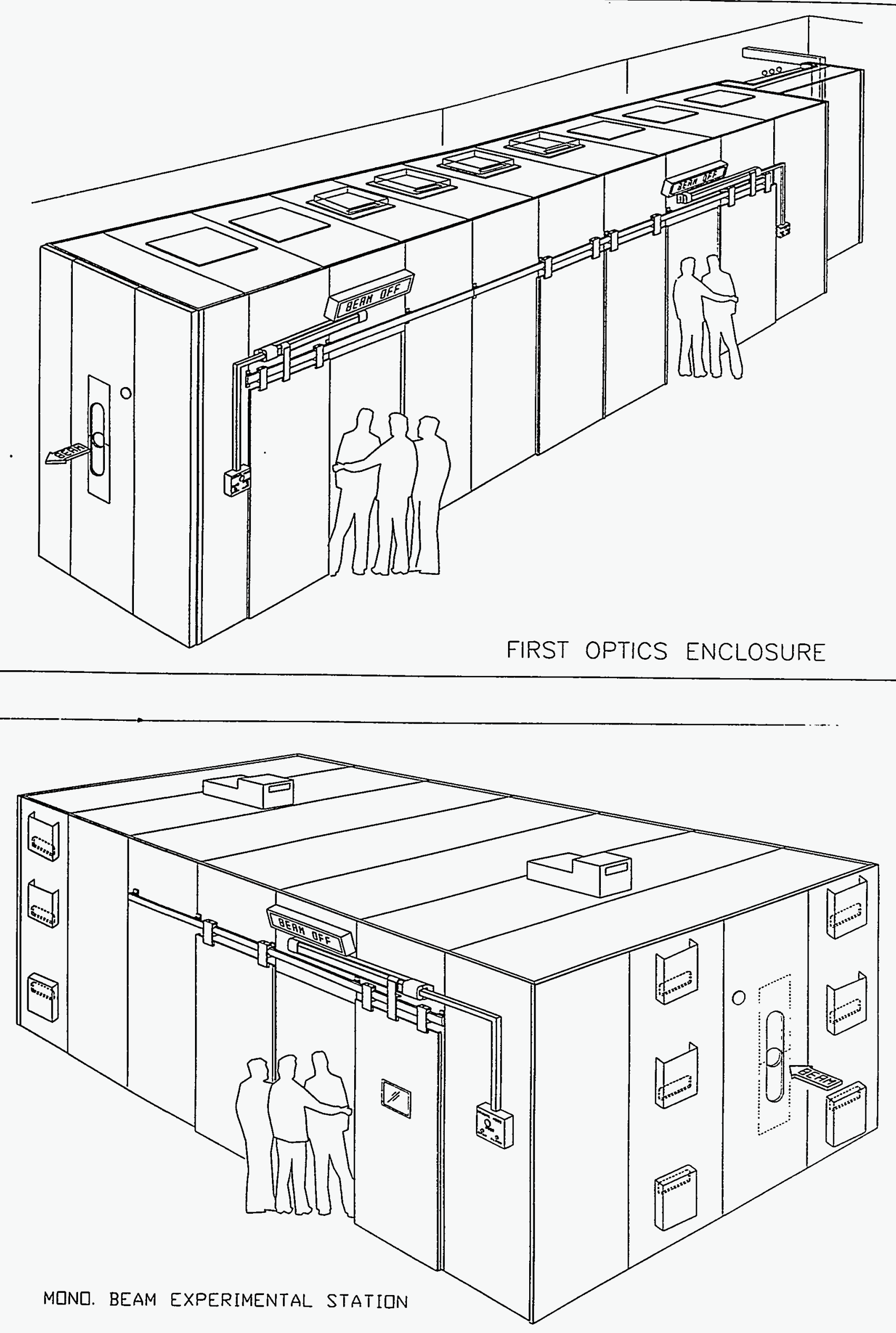